\title{
OPERATION OF CANDU POWER REACTOR IN THORIUM SELF-SUFFICIENT FUEL CYCLE
}

\author{
Boris Bergelson, Alexander Gerasimov, \\ Institute of Theoretical and Experimental Physics, \\ 25, B.Cheremushkinskaya, 117218 Moscow, Russia, \\ Phone: (095)127-0543, Fax: (095)127-0543 \\ E-mail:geras@itep.ru \\ Georgy Tikhomirov, Li Jinhong \\ Moscow Engineering Physics Institute
}

\begin{abstract}
Thorium self-sufficient mode of power reactors attracts an attention during last years due to considerably less amount of transuranium long-lived radioactive wastes, expanded fuel base of atomic power, and in connection with the problem of nonproliferation.

Results of calculation studies of CANDU reactor operation in thorium cycle are presented in the paper. Calculations were performed to validate feasibility of operation of heavy-water thermal neutron power reactor in self-sufficient thorium cycle.

Two modes of operation were considered: mode of preliminary accumulation of ${ }^{233} \mathrm{U}$ and mode of operation in self-sufficient cycle. For the mode of accumulation of ${ }^{233} \mathrm{U}$ it was assumed, that plutonium was used as additional fissile material. Plutonium was located in fuel channels, while ${ }^{232} \mathrm{Th}$ was located in target channels. For the mode of operation in self-sufficient cycle, it was assumed that all channels were loaded with the identical fuel assemblies with $\mathrm{ThO}_{2}$ and certain amount of ${ }^{233} \mathrm{U}$. Nonuniform distribution of ${ }^{233} \mathrm{U}$ in the fuel assembly seems to be more preferable. The results of calculations demonstrated practical feasibility of operation of heavy-water power reactor of CANDU type in self-sufficient thorium cycle with use of approved technologies.
\end{abstract}

Keywords: thorium fuel cycle, self-sufficient mode, CANDU.

\section{INTRODUCTION}

Isotope ${ }^{233} \mathrm{U}$ is a good nuclear fuel due to big number of secondary neutrons released in the fission. In thorium nuclear fuel cycle, it is formed from fertile isotope ${ }^{232} \mathrm{Th}$ by means of neutron capture with subsequent decay of intermediate ${ }^{233} \mathrm{~Pa}$. Thorium fuel cycle has essential advantages over traditional uranium-plutonium fuel cycle because of considerably less amount of transuranium long-lived radioactive wastes. Use of thorium fuel permits to expand fuel base of atomic power. The interest to Th-U fuel cycle, especially to self-sufficient thorium cycle without application of plutonium as additional fissile material, increases during last years in connection with problems of non-proliferation and protection of an environment.

Possibility of realization of thorium fuel cycle was many times discussed in scientific papers. In publications of last years, thorium was considered only as a raw material for feed of nuclear reactors operating in uranium-plutonium fuel cycle (Boczar, 2002). Such mixed mode allows to save natural uranium during electric power production. Possibility of operation of power reactor in thorium-uranium fuel cycle without feed by fissile materials was considered in preceding publications, for instance by Dastur (1995), Boczar (2002). However, this possibility was only declared without demonstration of concrete ways of achievement. 
In this paper, results of calculation studies of self-sufficient mode for heavy-water power reactor are presented. This reactor is hereinafter referred to as " $\mathrm{T}$ " reactor. Calculations were made using code complex MCCOOR, developed on the base of codes MCNP, COUPLE, ORIGEN-S. Parameters of active core and scheme of refuelling of current heavy-water power reactor HWPR (CANDU) with the heat power of 2776 MW (Directory, 1994) were used for calculations.

\section{MODE OF ACCUMULATION OF ${ }^{233} U$}

It is assumed in this paper, that initial amount of ${ }^{233} \mathrm{U}$ necessary for following self-sufficient operation of the reactor is previously produced in the reactor itself. So, two modes are considered below: mode of accumulation of ${ }^{233} \mathrm{U}$ and mode of self-sufficient operation.

In the mode of accumulation of ${ }^{233} \mathrm{U}$, tetragonal heavy-water lattice of reactor " $\mathrm{T}$ " is composed of channels of two types, evenly distributed over the active core. The half of channels are referred to as fuel channels, another half are referred to as target channels. Fuel channel contains fuel assembly composed of 37 fuel elements with power plutonium or enriched uranium. Target channel contains target assembly composed of 37 target elements. Each target element is made in form of zirconium tube filled with pellets of $\mathrm{ThO}_{2}$. Figure 1 demonstrates part of channel lattice with 16 channels and elementary cell accepted for calculations.

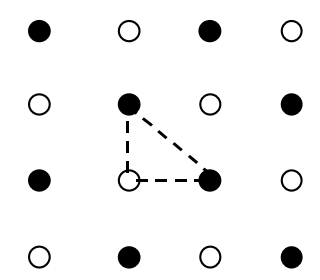

Fig.1. Lattice of channels in active core in the mode of accumulation of ${ }^{233} U$ and elementary cell accepted for calculations

Results of calculation of elementary cell of active core for the variant with using of fuel containing $10 \%$ of power plutonium are presented in Fig. 2.

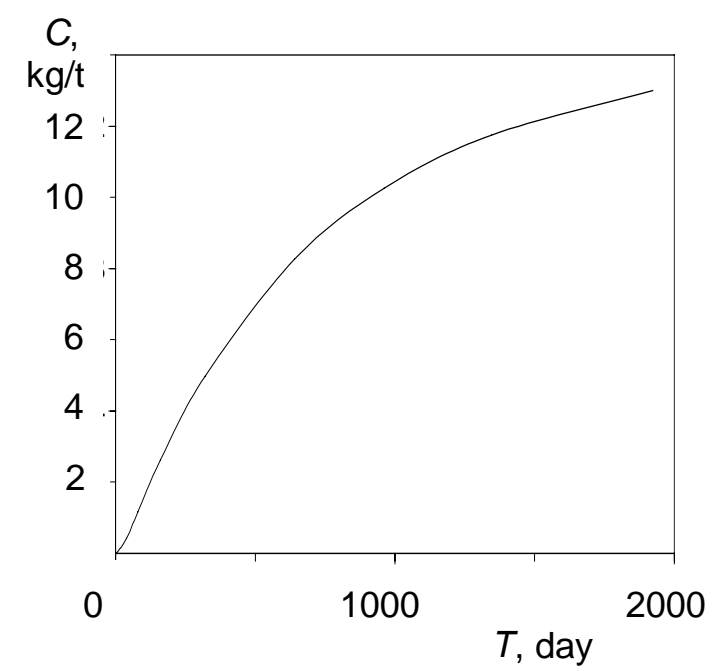

Fig.2. Variation of concentration of ${ }^{233} \mathrm{U}$ in $\mathrm{ThO}_{2}$ in the mode of accumulation of ${ }^{233} \mathrm{U}$

Content of ${ }^{233} \mathrm{U}$ more than $12 \mathrm{~kg} / \mathrm{t}$ in all channels of active core is required for start-up of reactor " $\mathrm{T}$ " in the self-sufficient mode. This means that for the accumulation of necessary amount of ${ }^{233} \mathrm{U}$, it will take, for instance, three cycles of irradiation of $\mathrm{ThO}_{2}$ targets during 2 years. Therefore in the mode of accumulation of ${ }^{233} \mathrm{U}$, reactor "T" should work approximately 6 years. Accumulated ${ }^{233} \mathrm{U}$ should be extracted from $\mathrm{Th}-{ }^{233} \mathrm{U}$ mixture for fabrication of fuel elements with certain content of ${ }^{233} \mathrm{U}$. 
It is apparent that considered parameters of operation of reactor " $\mathrm{T}$ " in the mode of accumulation of ${ }^{233} \mathrm{U}$ can be highly improved. It is possible to reduce time of accumulation of ${ }^{233} \mathrm{U}$ and increase power of reactor by following measures:

- increase of heat load on fuel element, in particular, at the expense of use of fuel elements with the diameter less than in current CANDU reactor;

- optimization of number and locations of target channels and fuel channels in active core;

- $\quad$ optimization of scheme of reloading of target channels;

- $\quad$ increase of number of targets in the target assembly (Boczar, 2002);

- reducing of plutonium (uranium) load in fuel elements, that would result in increase of thermal neutron flux in targets at the same power of reactor " $\mathrm{T}$ ".

\section{SELF-SUFFICIENT MODE}

In the self-sufficient mode, it is assumed that fuel elements containing $\mathrm{ThO}_{2}$ with the certain content of ${ }^{233} \mathrm{U}$ are loaded in all channels of the reactor.

Amount of ${ }^{233} \mathrm{U}$ and scheme of its accommodation in channels must ensure overcriticality of the reactor " $\mathrm{T}$ " in the initial state. Overcriticality of the current CANDU reactor in the cold condition with the fresh fuel (natural uranium), calculated by means of above mentioned code complex, makes $\Delta K \geq 0.1$. It is obvious that the reactor "T" should have overcriticality not less than this value.

In the reactor "T" under the acceptable burnup of ${ }^{233} \mathrm{U}$ and other fissile isotopes, reproduction of ${ }^{233} \mathrm{U}$ must ensure at least equality of contents of fuel in the active core before the beginning and after the end of lifetime. This condition together with the reactivity margin determines the lifetime. Breeding ratio and its variations during the lifetime depend on the amount of fuel, formed in the mode of accumulation of ${ }^{233} \mathrm{U}$, and of its accommodation in the active core of the reactor.

Fuel burnup and lifetime in the reactor "T" was estimated by the method, which is suitable for CANDU reactors with continuous bidirectional refuelling. In this case, fuel assemblies with different burnup are present in active core during the whole lifetime. Such condition can be described by average multiplication factor determined by the leakage of neutrons from the active core, absorption of neutrons by structure materials of active core and by control rods. For the CANDU reactor with control rods in active core, this value is 1.045, while for extracted control rods it equals 1.035 (Boczar, 2002). Fuel burnup $W_{0}$ in reactor "T" was estimated in accordance with the parameter $\alpha$

$$
\alpha=\int_{0}^{W_{0}} K_{\infty} d W / W_{0}
$$

where $W$ is fuel burnup. Dependence $K_{\infty}(W)$ was calculated in the interval between initial value $W=0$ corresponding to the fresh fuel, and final value $W_{0}$ corresponding to the fuel unloaded from the reactor. In the process of calculation of $K_{\infty}(W)$, neutronic parameters were calculated over again at different values of $W$ with the step of $1 \mathrm{MW} \cdot \mathrm{d} / \mathrm{kg}$ in order to take into account change of neutron spectrum in fuel.

Calculations were made for different burnups and for three variants of initial accommodation of ${ }^{233} \mathrm{U}$ in the active core of the reactor "T" (Fig.3).

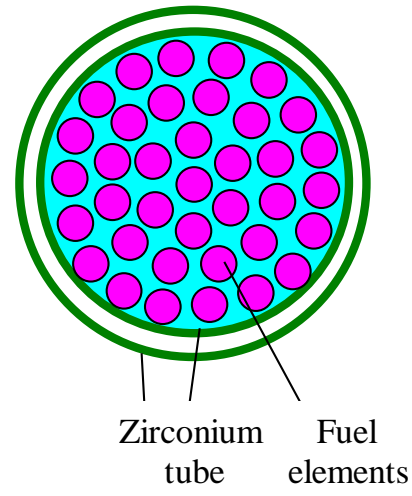

1 st variant

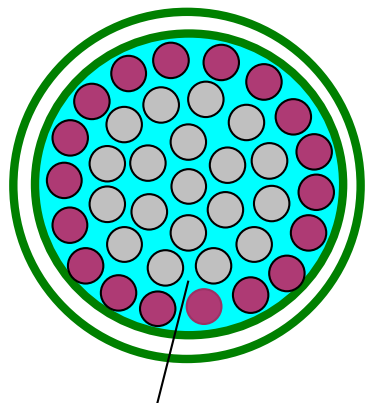

Heavy water coolant

2nd variant

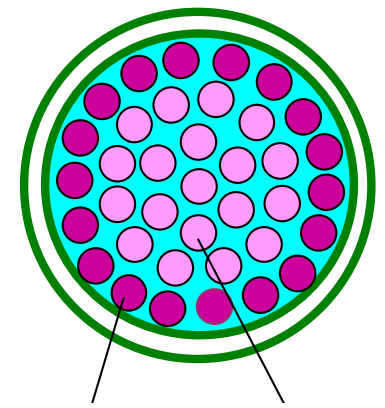

18 external fuel elements fuel elements

$3 r d$ variant

Fig.3. Three variants of initial accommodation of ${ }^{233} U$ 
In the first variant, accumulated ${ }^{233} \mathrm{U}$ is distributed in equal parts over all fuel assemblies of the reactor with the content $C=12 \mathrm{~kg} / \mathrm{t}$ in each fuel element.

In the second variant, accumulated ${ }^{233} \mathrm{U}$ is distributed in equal parts over all fuel assemblies of the reactor. However, in each fuel assembly, ${ }^{233} \mathrm{U}$ is placed only in 18 external fuel elements with the content $C=24 \mathrm{~kg} / \mathrm{t}$ while 19 internal fuel elements are filled only by $\mathrm{ThO}_{2}$ without ${ }^{233} \mathrm{U}$.

In the third variant, accumulated ${ }^{233} \mathrm{U}$ is distributed in equal parts over all fuel assemblies of the reactor. However, in each fuel assembly, ${ }^{233} \mathrm{U}$ is placed in 18 external fuel elements with the content $C=16 \mathrm{~kg} / \mathrm{t}$, and in 19 internal fuel elements with the content $C=10 \mathrm{~kg} / \mathrm{t}$. Balance on the uranium is ensured due to changing of density of ${ }^{233} \mathrm{U}+\mathrm{ThO}_{2}$ (Table 1, Fig. 4, 5).

Table 1. Fuel burnup and heat power of the reactor for three variant of fuel arrangement

\begin{tabular}{|c|c|c|c|c|}
\hline \multirow{2}{*}{ Reactor } & \multicolumn{3}{|c|}{ Fuel burnup, MW·d/kg } & Heat power for $\alpha=1.035$, \\
\cline { 2 - 4 } CANDU & $\alpha=1.025$ & $\alpha=1.035$ & $\alpha=1.045$ & MW \\
\hline "T", variant & 9.4 & 8.1 & 6.7 & 1750 (Directory, 1994) \\
1 & 3.4 & 1.5 & 0.7 & 2760 (Directory, 1994) \\
2 & 17.5 & 14 & 11 & $1400-1900$ \\
3 & 10.1 & 6.7 & 4 & $1900-2000$ \\
\hline
\end{tabular}

Calculated fuel burnup of the CANDU reactor with natural uranium is in good accordance with operating value of $8.3 \mathrm{MW} \cdot \mathrm{d} / \mathrm{kg}$ (Directory, 1994). So, there is good reason to think that fuel burnups calculated for three variants of fuel accommodation in fuel assemblies of the reactor " $\mathrm{T}$ " using the same method with same neutronic constants, are close to real values. Data of Table 1 demonstrate that under even distribution of ${ }^{233} \mathrm{U}$ over all fuel elements of the reactor "T" (first variant), fuel burnup is unacceptably low, while initial overcriticality of active core is less than $10 \%$ (curve 1 in Fig. 4). Fuel burnup can be increased to $15 \mathrm{MW} \cdot \mathrm{d} / \mathrm{kg}$ due to nonuniform distribution of the same amount of ${ }^{233} \mathrm{U}$ within the fuel assembly (second variant), i.e. shielding of internal fuel elements allows to increase burnup approximately by 10 times. At nonequal load of ${ }^{233} \mathrm{U}$ into external and internal fuel elements in each assembly (third variant), in which shielding of internal fuel elements is less than in the second variant, burnup decreases by 1.5 times. As one would expect, heat power of the reactor " $\mathrm{T}$ " for the third variant is much higher than for the second variant.

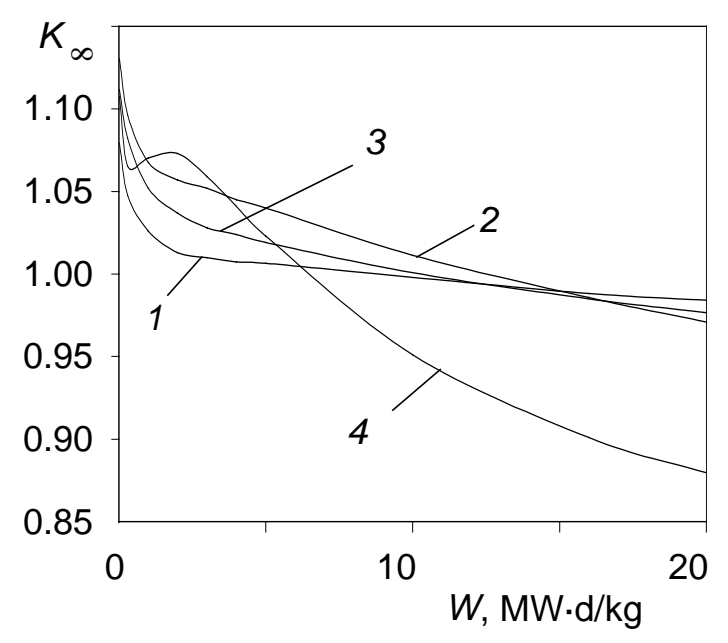

Fig.4. Variation of multiplication factor for elementary cel in the self-sufficient mode: $1,2,3-1 s t, 2 n d$, and $3 r d$ variant of ${ }^{233} U$ arrangement in fuel assemblies of the " $T$ " reactor, $4-C A N D U$ reactor with natural uranium. 


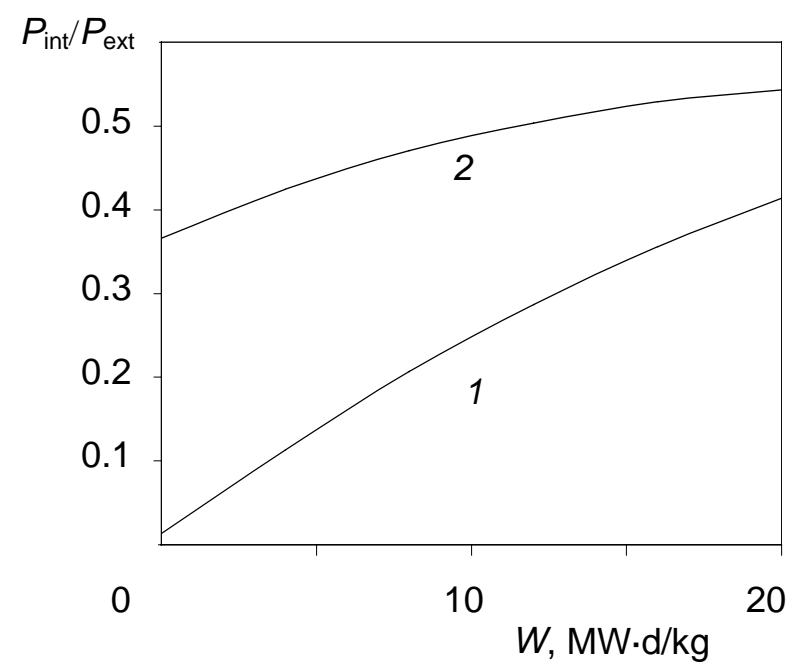

Fig.5. Ratio of total power of 19 internal fuel elements to total power of 18 external fuel elements in fuel assembly in the self-sufficient mode: $1,2-2$ nd and 3 rd variant of ${ }^{233} U$

arrangement in fuel assemblies of the " $T$ " reactor.

It is obvious that possibility of practical realization of self-sufficient mode in the reactor " $\mathrm{T}$ " depends mainly on the amount of fissile isotopes in the fuel unloading from the active core in the end of the next lifetime. The curves in Fig.6 describe changes of total amount of ${ }^{233} \mathrm{U},{ }^{235} \mathrm{U}$, and ${ }^{233} \mathrm{~Pa}$ during the lifetime for the second and the third variants of fuel accommodation (initial value is accepted as 100\%). These changes do not exceed 1-2\% of initial amount, i.e. they are within the error interval of our calculations. So, these results can be considered as preliminary data, demonstrating possibility of operation of the reactor " $\mathrm{T}$ " in self-sufficient mode.

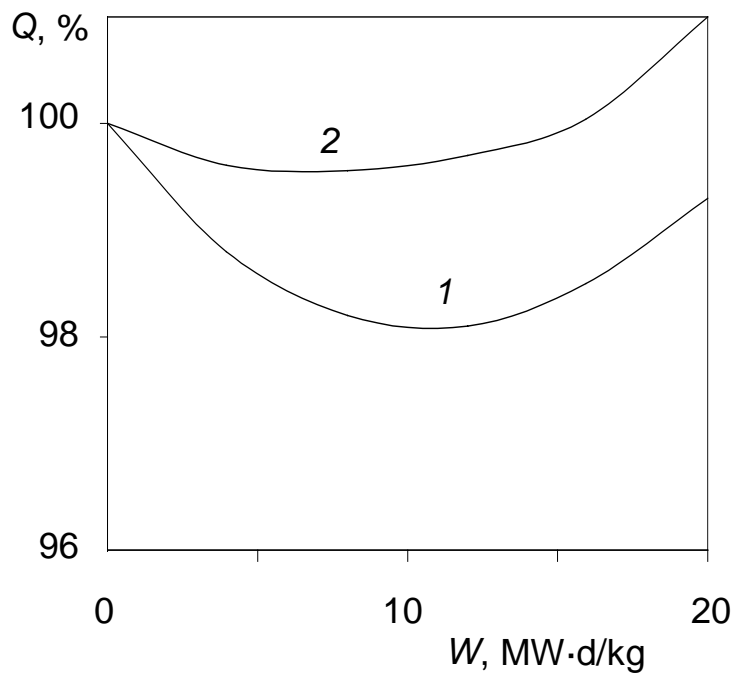

Fig.6. Variation of the total mass of ${ }^{233} U,{ }^{235} U,{ }^{233} \mathrm{~Pa}$ during the lifetime: $1,2-2$ nd and $3 \mathrm{rd}$ variant of ${ }^{233} U$ arrangement in fuel assemblies of the " $T$ " reactor.

For obtaining additional data, calculations of multiplication factors $K_{\infty}(0)$ and $K_{\infty}\left(W_{0}\right)$ were made for the third variant of fuel accommodation in cold reactor "T". Fuel burnup of $8 \mathrm{MW} \cdot \mathrm{d} / \mathrm{kg}$ was accepted in these calculations. This value corresponded to the lifetime of 430 days (Table 2). Nuclides ${ }^{233} \mathrm{U},{ }^{235} \mathrm{U}$, and ${ }^{233} \mathrm{~Pa}$ extracted from unloaded fuel of each preceding lifetime were used as fuel for the following lifetime. In the Table 3, composition of uranium isotopes extracted from unloaded fuel after the 1st, 5th, and 10th lifetimes is presented. Total mass of all isotopes of uranium at the beginning of the first lifetime is accepted as $100 \%$. 
Table 2. Multiplication factor in the beginning and in the end of fuel lifetimes

\begin{tabular}{|c|c|c|}
\hline Number of lifetime & Beginning & End \\
\hline 1 & 1.120 & 1.005 \\
2 & 1.103 & 1.006 \\
5 & 1.103 & 1.010 \\
10 & 1.102 & 1.009 \\
\hline
\end{tabular}

Table 3. Isotopic composition of the uranium

\begin{tabular}{|c|c|c|c|c|c|}
\hline Number of lifetime & ${ }^{232} \mathrm{U}$ & ${ }^{233} \mathrm{U}$ & ${ }^{234} \mathrm{U}$ & ${ }^{235} \mathrm{U}$ & ${ }^{236} \mathrm{U}$ \\
\hline 1 & 0.002 & 99.7 & 6.5 & 0.4 & 0.02 \\
5 & 0.060 & 100.3 & 23.1 & 3.6 & 0.9 \\
10 & 0.085 & 100.5 & 34.7 & 6.0 & 3.1 \\
\hline
\end{tabular}

The data of Tables 2 and 3 are in fact calculating substantiations of feasibility of self-sufficient mode for heavy-water power reactor of CANDU type operating in thorium-uranium fuel cycle.

\section{CONCLUSIONS}

The power and fuel burnup obtained for the reactor " $\mathrm{T}$ " give only estimation of real values. As with the mode of accumulation of ${ }^{233} \mathrm{U}$, use of the parameters of current CANDU reactor for the determination of conditions, in which self-sufficient mode is possible, does not allow to obtain solutions close to optimum. However, it should bear in mind that authors stated limited task: to demonstrate practical feasibility of self-sufficient mode in heavy-water power reactor of CANDU type on the base of proven technology. So, optimization calculations with account of economic considerations were not performed in this stage of investigation. At the same time, experience of calculation study of such systems allows to make the following conclusion. The development of advanced heavy-water reactor with account of specific requirements of mode of ${ }^{233} U$ accumulation and self-sufficient mode will allow to improve highly such most important parameters as time of fuel accumulation, burnup, and power. Herewith problems connected with the safety should also be solved.

Self-sufficient mode is related with rather big effort on the extraction of isotopes of uranium from unloaded nuclear fuel. However, because of need of accumulation of required amount of ${ }^{233} \mathrm{U}$, this disadvantage is inherent not only to considered modes, but also to thorium-uranium fuel cycle in any its modification.

\section{REFERENCES}

[1] Boczar, P., et al., (2002), Proc. of Three IAEA Meetings on Thorium Fuel Utilization: Options and Trends. IAEA-TECDOC-319, pp.104-120.

[2] Dastur, A., Menely, D., Bass, D., (1995), Proc. of the Intern. Conf. on Evaluation of Emerging Nuclear Fuel Cycle Systems (Global'95), v.2, pp.1908-1917.

[3] Directory of Nuclear Power Plants in the Word, (1994), Japan Nuclear Energy Information Centr. Co., Ltd, Tokyo, Japan. 